\title{
CARE4VALUE
}

\section{A CLINICAL INSTRUMENT DATA COLLECTION PLATFORM FOR LONG-TERM CARE UNITS}

$6^{\text {th }}$ ENBENG

IEEE PORTUGUESE MEETING IN BIOENGINEERING
Authors

Pedro H. Ferreira

Marisa Maximiano

Catarina I. Reis 


\section{AGENDA}

- Introduction

- Care4value - Specific and Technical Goals

- THE CARE4VALUE ECOSYSTEM

- Mobile Application

- Dashboard

- Conclusions and Future Work 


\section{INTRODUCTION}

- Costs in Healthcare are a major concern - tend to rise!

- Healthcare Units need to monitor and visualize costs and gains

- Daily usage of clinical instruments' data (scales)

- Assess the clinical condition of a patient

\section{CARE4VALUE GOALS}

- Predictive measurement of costs based on the clinical condition of a patient

- Data collection >> Mobile Application + Clinical Support System 


\section{CLINICAL CONDITION - Clinical Instruments / Scales}

\begin{tabular}{|c|c|c|c|}
\hline Physical & Spirituality & Social & Mental \\
\hline $\begin{array}{ll}\text { - } & \text { Barthel Index } \\
\text { - } & \text { Braden } \\
\text { - } & \text { MUST / MNA } \\
\text { - } & \text { Skin Integrity } \\
\text { Screening Question / } \\
\text { Pressure Ulcers } \\
\text { - } \quad \text { Charlson Comorbidity } \\
\text { Index } \\
\text { - } & \text { Pain } \\
\text { (Numeric Rating Scale) }\end{array}$ & $\begin{array}{l}\text { - "Escala de Avaliação } \\
\text { da Espiritualidade" } \\
\text { (Spirituality Scale) }\end{array}$ & $\begin{array}{ll}\text { - } & \text { Gijón } \\
\text { - } & \text { Family } \\
& \text { Relationship Scale }\end{array}$ & $\begin{array}{l}\text { - Depression Screening } \\
\text { Question } \\
\text { - Mini-Mental State } \\
\text { Examination }\end{array}$ \\
\hline
\end{tabular}

* EQ-5D e Zarit Burden Interview 


\section{CARE4VALUE - Specific Goals}

- Enhance value creation in Long-Term Care (LTC) providers

- Pilot project = intervention to be carried out in a specific LTC unit

- Categorization of patients within different levels of clinical condition

- Predict the direct impact (cost) of the patient's care

- Support decision making by top level management and practitioners 


\section{CARE4VALUE - Technical Goals}

- Centralized data model

- Data collection through:

- a tailored mobile app;

- and manual import of existing data in the available clinical systems.

- Analysis and reporting through a dashboard, revealing the relationship between costs and health outcomes

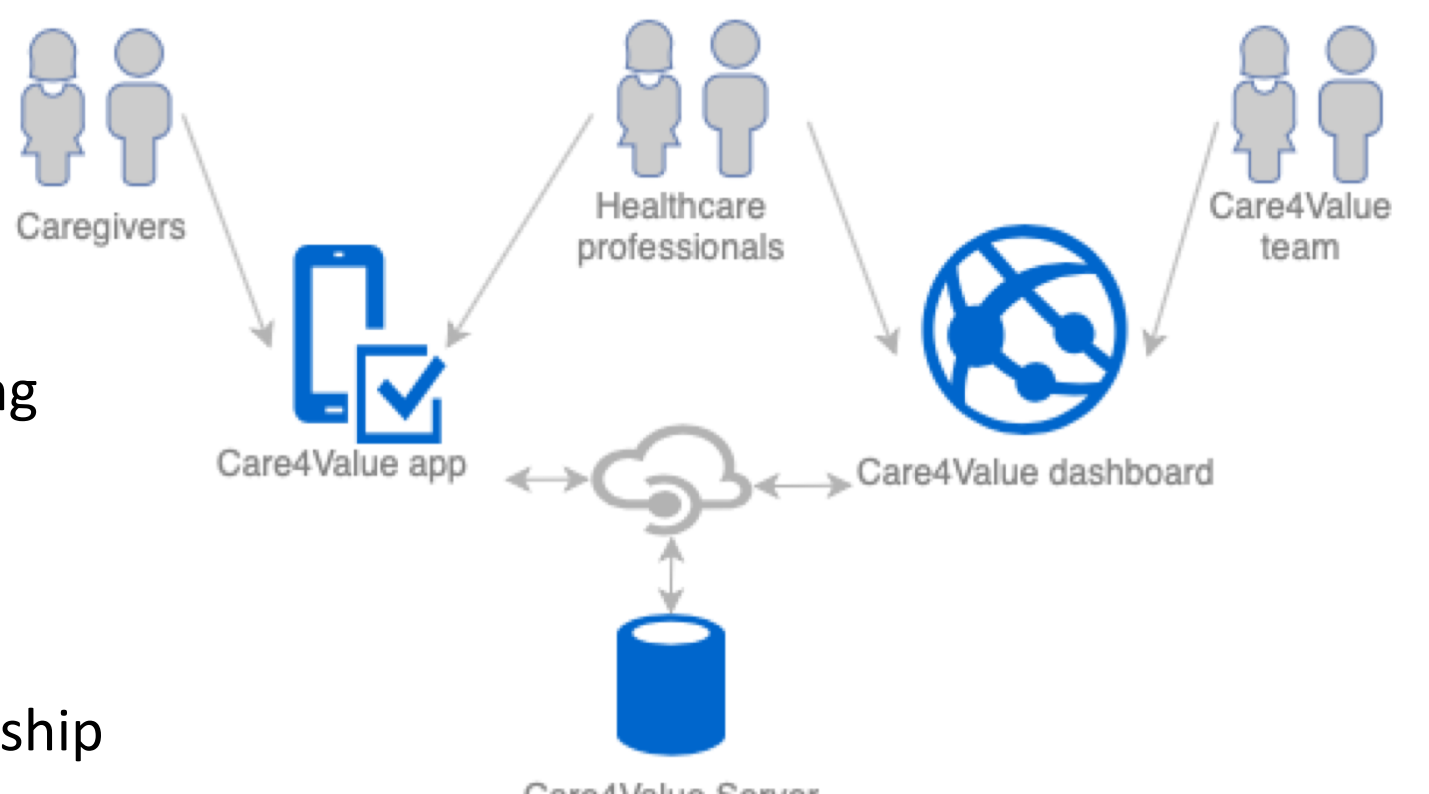




\section{THE CARE4VALUE ECOSYSTEM}

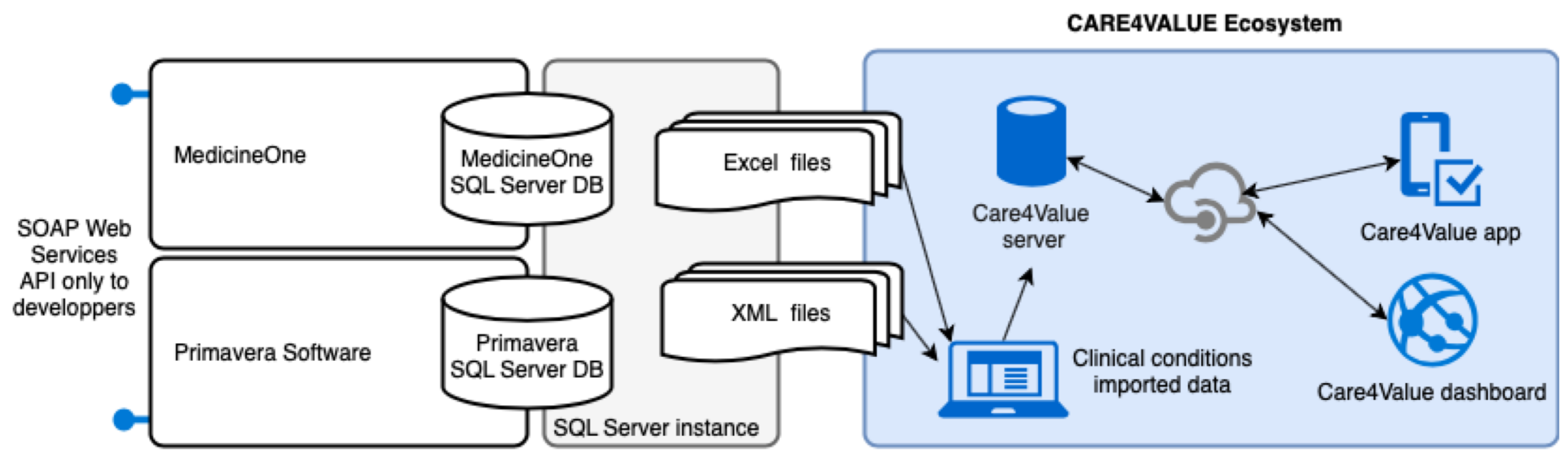




\section{THE CARE4VALUE ECOSYSTEM - Mobile Application}

- List of clinical instruments (scales) that health professional needs daily

- Collects patient data and submits it directly to a centralized location

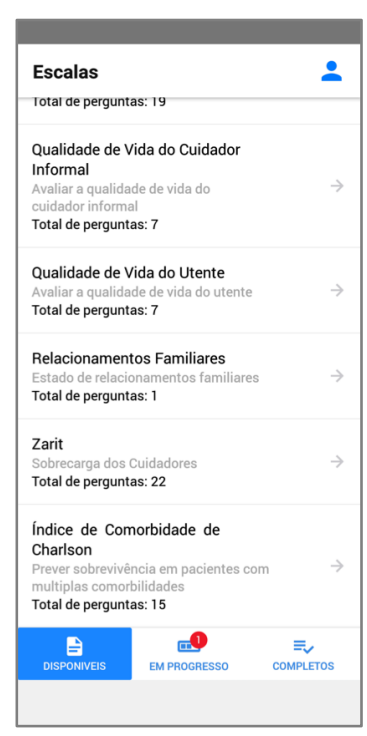

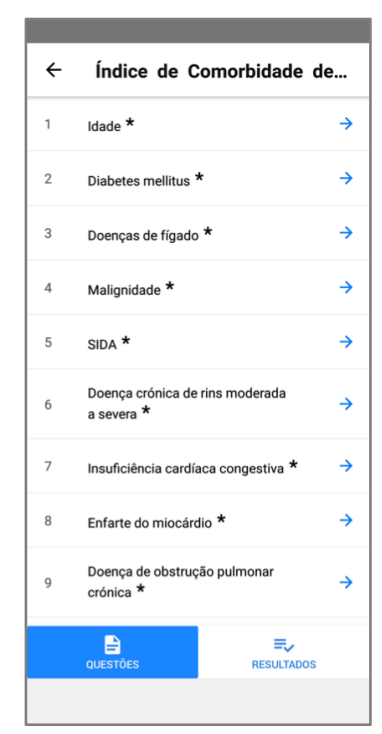
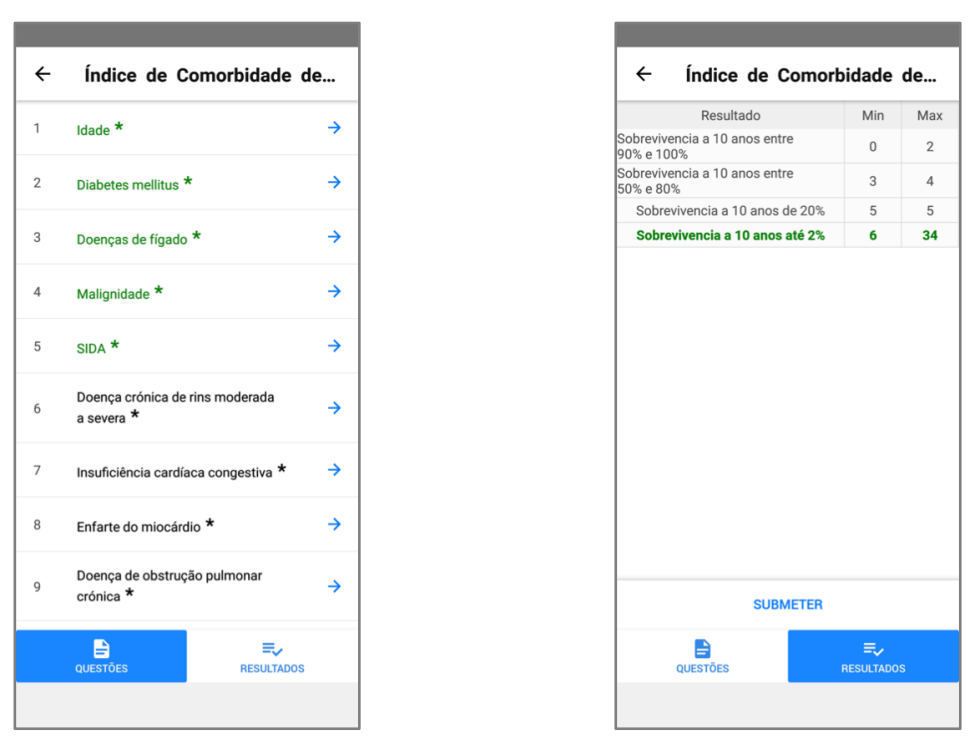


\section{THE CARE4VALUE ECOSYSTEM - Dashboard}

- Data visualization (export to known formats)

- Profiling of patients based on their clinical condition*

- Management of users and clinical instruments
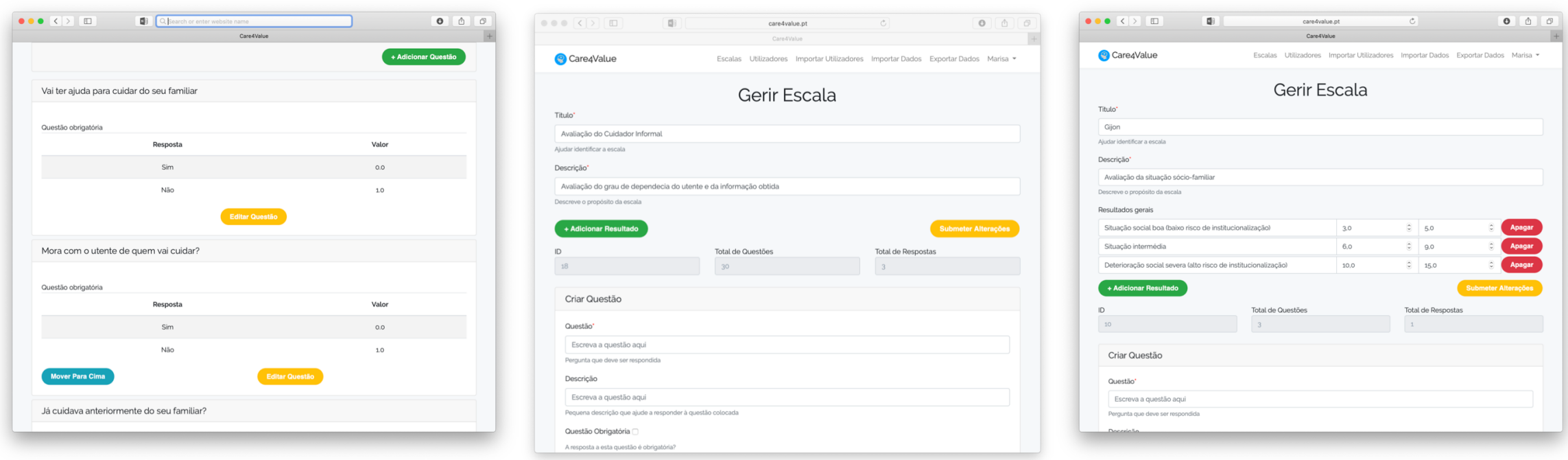

* Patient's cost estimation (at the end of the project) 


\section{CONCLUSIONS AND FUTURE WORK}

- Ongoing project! But the platform is deployed and in use!

- The pilot-study phase is already helping to improve the developed ecosystem based on the obtained feedback

- The need to exchange data with other systems (interoperability) is one of the major security concerns in this project

- Valuable insights on the clinical monitoring of patients and their caregivers

- Add value to the visualization of the information

- Future: new features for the dashboard and other LTC locations 


\section{CARE4VALUE}

\section{A CLINICAL INSTRUMENT DATA COLLECTION PLATFORM FOR LONG-TERM CARE UNITS}

$6^{\text {th }}$ ENBENG

IEEE PORTUGUESE MEETING IN BIOENGINEERING
Authors

Pedro H. Ferreira

Marisa Maximiano

Catarina I. Reis 